\title{
Effects of Copaiba oil in the healing process of urinary bladder in rats
}

\author{
Denilson José Silva Feitosa Junior ${ }^{1}$, Luan Teles Ferreira de Carvalho ${ }^{1}$, Ingrid Rodrigues de Oliveira Rocha ${ }^{1}$, \\ Camila Noura de Brito ${ }^{1}$, Rodrigo Alencar Moreira ${ }^{2}$, Charles Alberto Villacorta de Barros ${ }^{3}$ \\ ${ }^{1}$ Laboratório de Cirurgia Experimental, Universidade Estadual do Pará, Belém, PA, Brasil; ${ }^{2}$ Departamento \\ de Pesquisa Cirúrgica e Experimental, Universidade Estadual do Pará, Belém, PA, Brasil; ${ }^{3}$ Departamento \\ de Cirurgia Experimental e Anestesiologia, Universidade Estadual do Pará, Belém, PA, Brasil
}

\section{ABSTRACT}

Introduction: The appropriate closure of the urinary bladder is important to many urologic procedures to avoid the formation of fistulas and strictures by excessive fibrosis. This paper presents the alterations in the bladder healing process of rats after the topical use of Copaiba oil (Copaifera reticulata).

Material and Methods: Ten male Wistar rats were used and randomly divided into two groups: Control group (CG): injected $1 \mathrm{ml} / \mathrm{kg}$ of saline solution on the suture line; and Copaiba group (CpG): $0.63 \mathrm{ml} / \mathrm{kg}$ of copaiba oil applied to the suture line. Euthanasia was performed on the seventh day after surgery. The criteria observed were adherences formation, histopathological modifications and stereology for collagen.

Results: Both groups showed adhesions to the bladder, with no statistically significant difference $(p=0.1481)$. The microscopic evaluation revealed a trend to more severe acute inflammation process on the $\mathrm{CpG}$, but there was statistical difference only in the giant cells reaction $(p=0.0472)$ and vascular proliferation $(p=0.0472)$. The stereology showed no difference.

Conclusion: The copaiba oil modified the healing process, improving the quantity of giant cells and vascular proliferation, but not interfered in the collagen physiology.

\section{ARTICLE INFO}

\section{Keywords:}

Urinary Bladder; Wound Healing;

Plants, Medicinal; Collagen

Int Braz J Urol. 2017; 43: 384-9

Submitted for publication:

March 09, 2017

Accepted after revision:

June 08, 2017

Published as Ahead of Print:

August 28, 2017

\section{INTRODUCTION}

The appropriate closure of the urinary bladder is important to many urologic procedures to avoid the formation of fistulas and strictures by excessive fibrosis (1). Although healing occurs similarly in different tissues, some organs have their peculiarities. In the case of the urinary bladder, scarring may be impaired by the presence of urine (2). Although when compared with healing of the intestines, the bladder has a faster healing rate and tensile strength gain (3).

Regenerative medicine has been trying alternatives to common suture threads to impro- ve the rapid regeneration of the bladder, such as adhesives and barbed sutures (4). In addition, the use of medicinal plants in bladder healing has shown interesting results in experimental research $(5,6)$.

The copaiba oil (Copaifera sp.) is a native Amazonic herb and has many proprieties described such as anti-inflammatory, antibiotic, wound healing and anti-neoplastic (7). The majority of these were already scientifically described in experimental and clinical research, but none of that research tested this oil on the bladder healing process. To develop knowledge about the potential benefits of this plant, we evaluated the use 
of copaiba oil in the healing process of the urinary bladder in rats by macro- and microscopic analysis, regarding the formation of adherences, histopathological characteristics and stereology for collagen. This paper presents the alterations on the inflammatory response and collagens physiology in the bladder healing process of rats after the topical use of copaiba oil (Copaifera reticulata).

\section{MATERIAL AND METHODS}

\section{Animals}

Ten male Wistar rats (Rattus norvegicus), weighing between $200 \mathrm{~g}$ and $250 \mathrm{~g}$, were used in this study. The animals were housed in steel cages, cleaned twice a week, and put in a controlled environment with a temperature of $22 \pm 2^{\circ} \mathrm{C}$, with adequate humidity and artificial light in a photoperiod of 12/12 hours. Water and food were offered ad libitum throughout the study. The experimental procedures started only after the approval of this research by the Ethics Committee in Animal's Use from the Pará State University by the protocol 25/2015.

\section{Experimental design}

Rats were randomly divided into two groups, with five animals each. Groups were established as follows: Control group (cystotomy was performed followed by suture and the injection of $1 \mathrm{mg} / \mathrm{kg}$ of saline solution directly on the suture. $\mathrm{N}$ : 5) and Copaiba group (cystotomy was performed followed by suture and the injection of $1 \mathrm{mg} /$ $\mathrm{kg}$ of copaiba oil directly on the suture. N: 5).

\section{Copaiba oil}

The Copaiba Oil was obtained commercially from Amazon $\mathrm{Oil}^{\circ}$. The oil was extracted in the city of Itaituba, Brazil and was certified by a chemical engineer. Its composition was $45 \%$ of $\beta$-caryophyllene.

\section{Surgery procedure}

The animals were anesthetized by intraperitoneal injection of ketamine $(70 \mathrm{mg} / \mathrm{kg})$ and xylazine $(10 \mathrm{mg} / \mathrm{kg})$. Then, the rats were put in supine position on a surgical board. The trichotomy and antisepsis of the lower third of the abdominal region were performed and a median incision of $2 \mathrm{~cm}$ made to expose the bladder (Figure-1A). Then, an $1 \mathrm{~cm}$ cystotomy was performed and sutured with 4-0 Polydioxanone - PDS $\odot$ (Figure-1B). For the cystotomy instead of incising the serosa, muscular and mucosa at one time, we divided this step into two stages, reserving an incision only for the mucosa. Immediately following, either the saline solution or copaiba oil were injected, depen-

Figure 1 - Urinary bladder before (A) and after the cystotomy and suture with PDS ${ }^{\odot}$ (B).

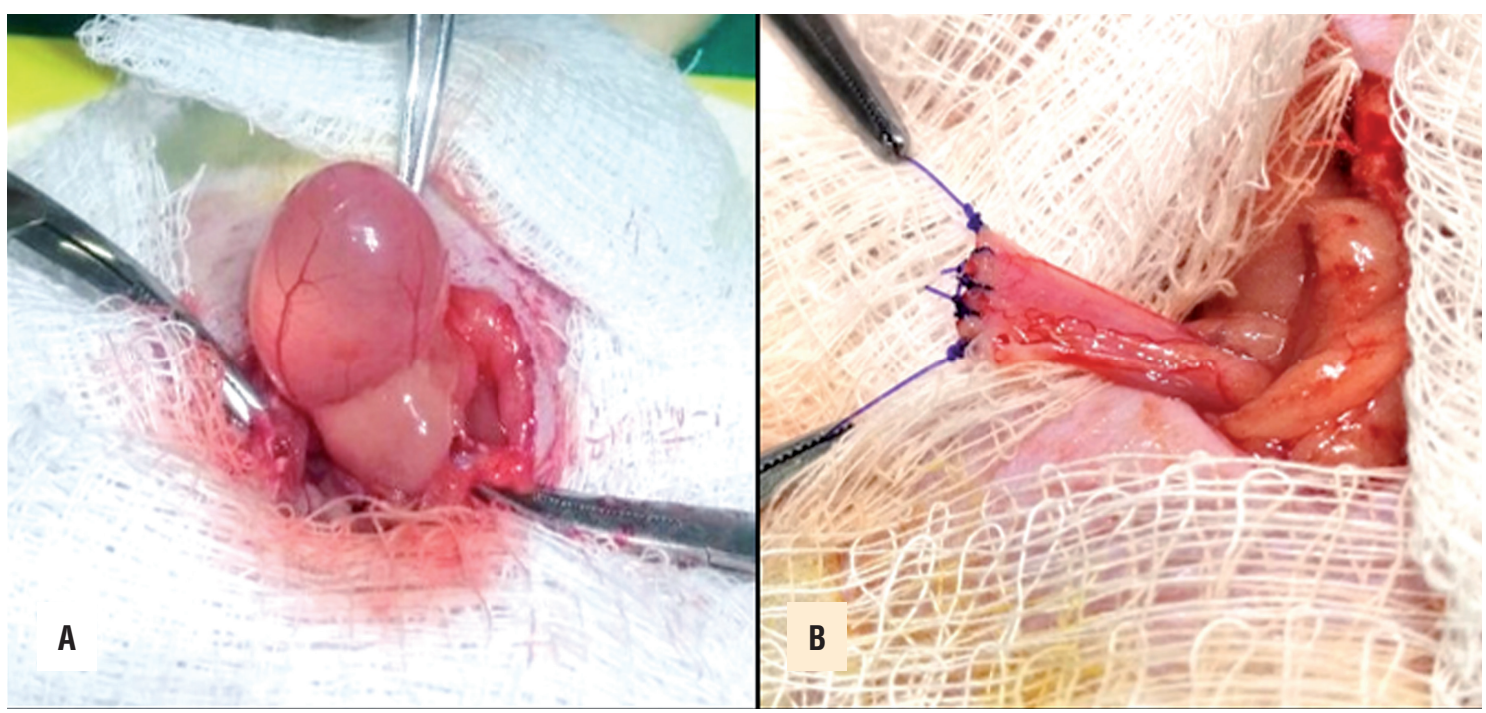


ding on the group. Then, all the animals had their abdominal wall closed with 4-0 nylon in continuous suture for the muscle-aponeurotic plane and separated for the skin.

\section{Macroscopic analysis}

On the seventh day after surgery, the rats were euthanized by an overdose of halothane by inhalation. Then, the macroscopic analysis began with inspection of the abdominal scar and verification of presence or absence of infection in the cavity. With the abdominal wall opened, we proceeded to evaluate adhesion formation, using the Nair score (8) (Table-1).

Table 1 - Nair score (Nair; Bath and Aurora, 1974).

\begin{tabular}{lr}
\hline Score & Morphological finds \\
\hline 0 & Absence of adhesions \\
1 & $\begin{array}{r}\text { Single band of adhesions, between viscera, or from } \\
\text { one viscus to abdominal wall }\end{array}$ \\
2 & Two bands, either between viscera of rom viscera to \\
& abdominal wall \\
3 & $\begin{array}{r}\text { More than two bands, between viscera, or viscera } \\
\text { mass withoul being adherent to abdominal wall }\end{array}$ \\
4 & Viscera directly adherent to abdominal wall, \\
& irrespective of number and extent of adhesive bands
\end{tabular}

\section{Microscopic analysis}

After total cystectomy, the bladder was fixed in $10 \%$ formalin by $48 \mathrm{~h}$ and the suture threads were removed. The piece was cleaved into three parts, contemplating the border, center and incision of the bladder. The tissues were dehydrated, diaphanized in xylol and parafinized. Then, the tissues were cut into $5 \mu \mathrm{m}$ sections at $250 \mu \mathrm{m}$ intervals, mounted on slides and stained with hematoxylin/eosin and Masson's trichrome stains.

The criteria observed were acute inflammation, necrosis, foreign-body giant cell reaction, re-epithelialization and vascular proliferation in hematoxylin/eosin stain. Fibro- blast and collagen growth was estimated in the Masson's trichrome stain. Each item was graded from 1 to 4, as follows: 1- absent; 2- mild; 3- moderate; 4- intense.

\section{Stereology}

Five sections stained with Masson's trichrome were randomly analyzed from each bladder. In each section, five fields were analyzed, totaling 15 fields per bladder. The analyzed fields were digitized to a final magnification of $\mathrm{x} 100$ using a video camera coupled to a light microscope.

The volumetric density of the collagen fibers and muscle fibers in the muscular layer was analyzed by overlaying the M- 42 grid system on the computed morphological image of the slides. The volumetric density was the relative density taken up by fibers in the tissue under examination. The stereological method determined quantitatively the parameters of the anatomical structural based on the two-dimensional thin sections, in three dimensions.

The equation $V v=\frac{P S}{P p} \times 100 \%$ was used to calculate the volume density of the collagen fibers, where: Vv=volumetric density, Ps=the number of structure points studied (collagen) and $\mathrm{Pp}=$ the number of possible test points (42 in this case).

\section{Statistical analysis}

The statistical analysis was made in the software Bioestat ${ }^{\odot}$ 5.3. The Mann-Whitney test was used, with $\mathrm{p}<0.05$ as the criterion for significance for all statistical comparisons.

\section{RESULTS}

\section{Macroscopic analysis}

There was no infection on the abdominal surgical wound in either group. In both the control and copaiba groups, we observed adhesion to the bladder with the omentum and the abdominal wall, with no statistically significant difference $(p=0.1481)$. The categories of adhesions following the Nair Score found in each group are described in Table-2. 
Table 2 - Categories of adhesion according the Nair score in both groups.

\begin{tabular}{lcc}
\hline & Control Group & Copaiba Group \\
\hline Rat 1 & 1 & 2 \\
Rat 2 & 2 & 1 \\
Rat 3 & 1 & 1 \\
Rat 4 & 1 & 2 \\
Rat 5 & 1 & 2 \\
\hline
\end{tabular}

Mann-Whitney test, $p=0.1481$

\section{Microscopic analysis}

From the histopathological parameters analyzed, the only differences identified between the groups were the giant cells reaction $(\mathrm{p}=0.0472)$ and vascular proliferation $(\mathrm{p}=0.472)$ (Figure-2). The statistical analysis of histological parameters, as well as the $p$ value for each variable, is summarized in Table-3.

\section{Stereology}

In the histological sections, we observed no differences between the groups $(\mathrm{p}=0.615)$ ( $\mathrm{Fi}$ gure-3). The fibers volumetric density in both groups is listed on Table-4.

\section{DISCUSSION}

The search for ways to improve the healing process and reduce its side effects dates to the
Hippocratic era; at present, there is no therapeutic method to fully control the harmful effects of the wound healing process. The search for new drugs should be encouraged for better control of wound inflammation, which in many cases causes surgical complications.

We know that the use of copaiba in the peritoneal cavity forms adherences because copaiba oil has a corrosive effect (9). However, there was no difference between the groups regarding the formation of adherences. This data disagree with other study that used copaiba oil directly on the peritoneal cavity, which caused the copaiba group to develop greater adherences (10). This probably occurred because the dosage of copaiba oil in our study was lower and concentrated in the bladder.

Regarding the microscopic analysis, the copaiba oil modified the healing process when compared with saline solution. The copaiba group showed statistically different results in the quantity of giant cells and vascular proliferation. The giant cells are activated macrophages which play an important role in modulating the inflammation process, performing down-regulation and protecting the tissue (11).

On the other hand, the higher vascular proliferation reinforces the idea that copaiba increases local inflammation, since the factors for vascular proliferation are mainly released by activated macrophages (12). Those data suggest that the topical administration of copaiba oil may have

Figure 2 - Histopathological slide of a rat urinary bladder from both the control (A) and copaiba (B) group. Note the vascular congestion and proliferation (black arrows) and the giant cell reaction (red arrow). Hematoxylin/Eosin stain 20x.

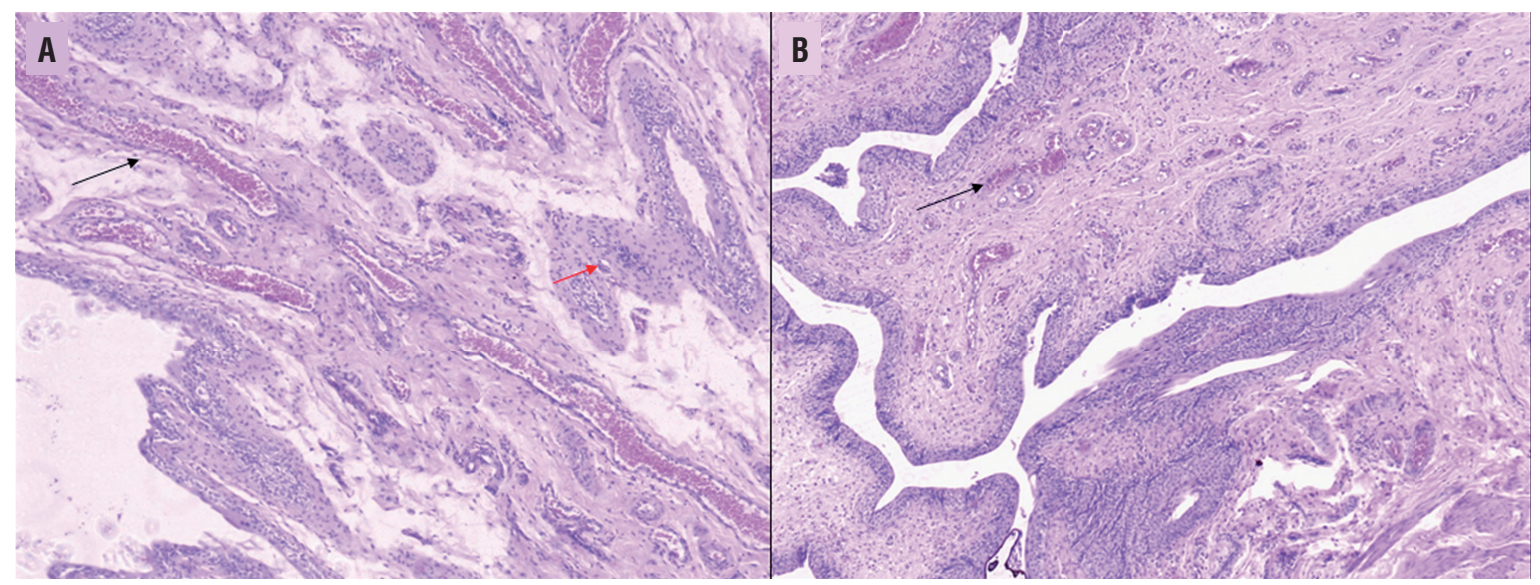


Table 3 - Statistical analysis of histological parameters by the Mann-Whitney test with the rank-sums of which group and the $\mathrm{p}$ value.

\begin{tabular}{lccc}
\hline Histological variables & Control Group rank-sum & Copaiba group rank-sum & $p$ \\
\hline Acute inflammation & 20.5 & 34.5 & 0.143 \\
Necrosis & 22.5 & 32.5 & 0.296 \\
Giant cells reaction & 18 & 37 & $0.047^{\star}$ \\
Fibroblasts & 25 & 30 & 0.601 \\
Collagen & 30 & 25 & 0.601 \\
Re-epithelialization & 23 & 32 & 0.347 \\
Vascular proliferation & 18 & 37 & $0.047^{*}$ \\
\hline
\end{tabular}

${ }^{*}$ significant statistical difference

Figure 3 - Histopathological slide of a rat urinary bladder from both the control (A) and copaiba (B) group. Note the collagen fibers (black arrow) and the vascular proliferation (red arrows). Masson's trichrome stain 20x.

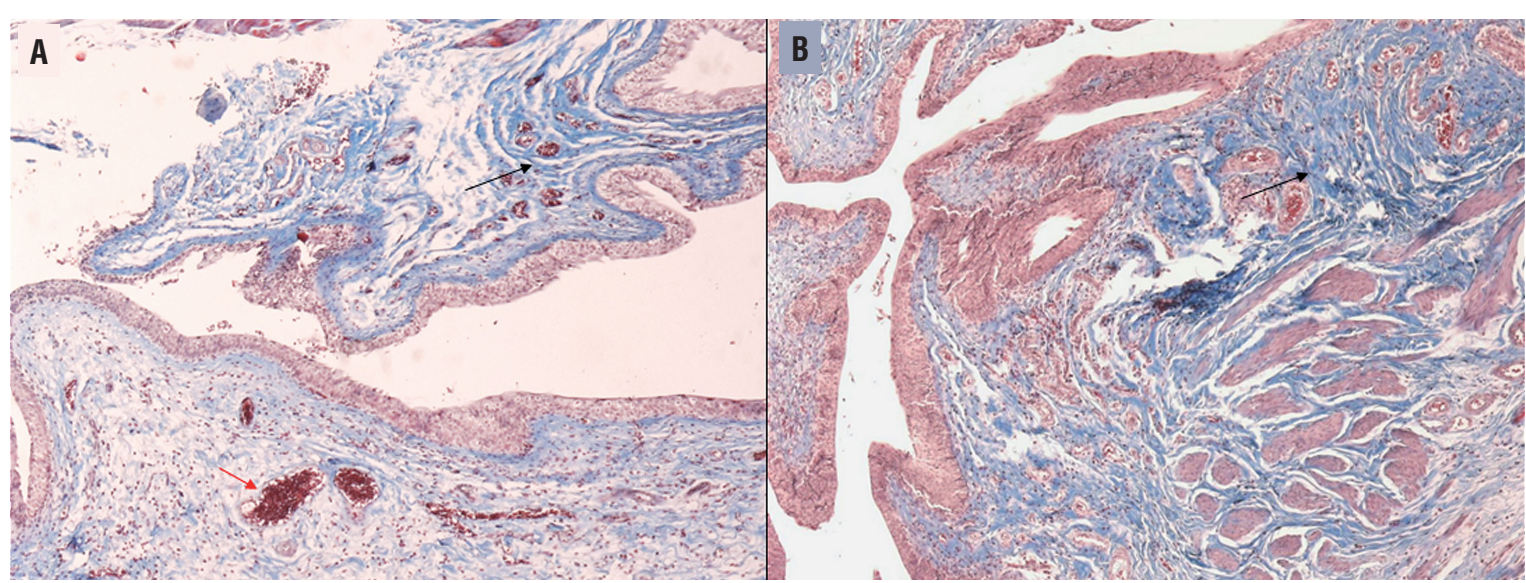

Table 4 - Volumetric density in percentage (Vv\%) of collagen in the bladder of control and copaiba groups.

\begin{tabular}{lcc}
\hline & Control Group & Copaiba Group \\
\hline Mean & 39 & 41 \\
Standard deviation & 6.38 & 6.34 \\
Standard error & 2.85 & 2.83 \\
Minimum & 29 & 31 \\
Maximum & 43 & 49 \\
\hline
\end{tabular}

Mann-Whitney test, $\mathrm{p}=0.615$ 
enhanced the inflammation due to its corrosive nature, which increased the inflammatory phase of healing and delayed the beginning of the proliferative phase.

The results might be different if the copaiba oil was administrated by gavage. Yasojima et al. (13) showed that the oral administration of copaiba modulates the inflammatory response and improves wound healing in abdominal wall defects.

In relation to the amount of collagen fibers, other studies showed that copaiba oil may improve the organization of those fibers in bone regeneration when topically applied, which was not observed in our results (14). Besides having a trending to have more collagen than the control group, there was not statistical difference in the total amount, as well as occurred in the quantity of fibroblasts. Then, in this study the copaiba oil did not enhance healing.

\section{CONCLUSIONS}

We conclude that the copaiba oil modified the healing process improving the quantity of giant cells and vascular proliferation, but not interfered in the collagen physiology.

\section{CONFLICT OF INTEREST}

\section{None declared.}

\section{REFERENCES}

1. Ninan N, Thomas S, Grohens Y. Wound healing in urology. Adv Drug Deliv Rev. 2015;82-83:93-105.

2. Holmes SA, James M, Whitfield HN. Potential use of tissue adhesive in urinary tract surgery. Br J Urol. 1992;69:647-50.

3. Hildreth BE 3rd, Ellison GW, Roberts JF, Adin CA, Holloway TJ, Archer LL, et al. Biomechanical and histologic comparison of single-layer continuous Cushing and simple continuous appositional cystotomy closure by use of poliglecaprone 25 in rats with experimentally induced inflammation of the urinary bladder. Am J Vet Res. 2006;67:686-92.
4. Petrut B, Hogea M, Fetica B, Kozan A, Feflea D, Sererman $G$, et al. In-vivo assessment of barbed suturing thread with regard to tissue reaction and material absorption in a rat model. Clujul Med. 2013;86:371-6.

5. Gonçalves Filho A, Torres OJ, Campos AC, Tâmbara Filho R, Rocha LC, Thiede A, et al. Effect of Passiflora edulis (passion fruit) extract on rats' bladder wound healing: morphological study. Acta Cir Bras. 2006;21(Suppl 2):1-8.

6. Lucena PL, Ribas Filho JM, Mazza M, Czeczko NG, Dietz UA, Correa Neto MA, et al. Evaluation of the aroreira (Schinus terebinthifolius Raddi) in the healing process of surgical incision in the bladder of rats. Acta Cir Bras. 2006;21(Suppl 2):46-51

7. Pieri F, Mussi M, Moreira M. Copaiba oil (Copaifera sp.): history, extraction, industrial applications and medicinal properties. Revista Brasileira de Plantas Medicinais. 2009;11:465-72.

8. Nair SK, Bhat IK, Aurora AL. Role of proteolytic enzyme in the prevention of postoperative intraperitoneal adhesions. Arch Surg. 1974; 108:849-53.

9. Silva NSR, Santos CF, Gonçalves LKS, Braga FS, Almeida JR, Lima CS, et al. Molecular Modeling of the Major Compounds of Sesquiterpenes Class in Copaiba Oil-resin. British Journal of Pharmaceutical Research. 7(4):247-263.

10. Yasojima EY, Teixeira RKC, Houat AP, Costa FLS, Yamaki VN, Feitosa-Junior DJS, et al. Copaiba oil influences ventral hernia repair with Vicryl $®$ mesh? ABCD Arquivos Brasileiros de Cirurgia Digestiva (São Paulo). 2015;28:186-9.

11. Fujiwara N, Kobayashi K. Macrophages in inflammation. Curr Drug Targets Inflamm Allergy. 2005;4:281-6.

12. Koh TJ, DiPietro LA. Inflammation and wound healing: the role of the macrophage. Expert Rev Mol Med. 2011;13:e23.

13. Yasojima EY, Teixeira RK, Houat Ade P, Costa FL, Silveira EL, Brito MV, et al. Effect of copaiba oil on correction of abdominal wall defect treated with the use of polypropylene/ polyglecaprone mesh. Acta Cir Bras. 2013;28:131-5.

14. Dias-da-Silva MA, Pereira AC, Marin MC, Salgado MA. The influence of topic and systemic administration of copaiba oil on the alveolar wound healing after tooth extraction in rats. $J$ Clin Exp Dent. 2013;5:e169-73.

Correspondence address: Denilson José Silva Feitosa Junior, MD Laboratório de Cirurgia Experimental Universidade do Estado do Para

Perebebuí, St. 2623, Belem, 66087-670, Brasil E-mail: denilsonfmed@gmail.com 